\title{
Dinitrogen as a universal electron acceptor in solid-state chemistry: an example of uncommon metallic compounds $\mathrm{Na}_{3}\left(\mathrm{~N}_{2}\right)_{4}$ and $\mathrm{NaN}_{2}$
}

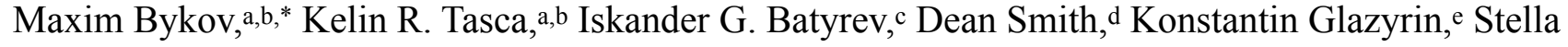 \\ Chariton, ${ }^{\mathrm{f}}$ Mohammad Mahmood, ${ }^{\mathrm{a}}$ Alexander F. Goncharovb \\ a Department of Mathematics, Howard University, Washington, DC 20059, USA \\ b The Earth and Planets Laboratory, Carnegie Institution for Science, Washington, DC 20015, USA \\ c U.S. Army Research Laboratory, RDRL-WML-B, Aberdeen Proving Ground Maryland, 21005 USA \\ d HPCAT, X-ray Science Division, Argonne National Laboratory, Argonne, IL 60439, USA \\ e Photon Science, Deutsches Elektronen-Synchrotron, 22607 Hamburg, Germany \\ ${ }_{\mathrm{f}}$ Center for Advanced Radiation Sources, University of Chicago, Lemont, IL 60437, USA
}

\begin{abstract}
With the exception of Li, alkali metals do not react with elemental nitrogen neither at ambient conditions nor at elevated temperatures, requiring the search for alternative synthetic routes to their nitrogen-containing compounds. Here using a controlled decomposition of sodium azide $\mathrm{NaN}_{3}$ at high pressure conditions we synthesize two novel compounds $\mathrm{Na}_{3}\left(\mathrm{~N}_{2}\right)_{4}$ and $\mathrm{NaN}_{2}$ both containing dinitrogen anions. $\mathrm{NaN}_{2}$ synthesized at $4 \mathrm{GPa}$ might be the common intermediate in high-pressure solid-state metathesis reactions where $\mathrm{NaN}_{3}$ is used as a source of nitrogen, while $\mathrm{Na}_{3}\left(\mathrm{~N}_{2}\right)_{4}$ opens a new class of compounds, where [N ] units accommodate a non-integer formal charge of -0.75 . This finding can dramatically extend the expected compositions in other group 1-2 metal-nitrogen systems. Electronic structure calculations show the metallic character for both compounds.
\end{abstract}

KEYWORDS: High-pressure chemistry, diazenides, nitrogen, nitrides, sodium azide, azides, pernitride, nitrogen fixation

\section{Introduction}

Homonuclear dinitrogen anions are common intermediates in biological and organo-metallic synthetic chemistry, and play an important role in the processes of nitrogen reduction to ammonia. ${ }^{1-3}$ In extended solid state compounds, nitrogen typically present in a form of a nitride anion $\mathrm{N}^{3}$ - and does not form catenated polyanions (with the exception of azides). The first alkaline-earth diazenides $\mathrm{SrN}, \mathrm{SrN}_{2}$ and $\mathrm{BaN}_{2}$ containing $\left[\mathrm{N}_{2}\right]^{2-}$ anions were synthesized from elements at high-pressure conditions only in the early 2000s.4,5 Later Schnick et al. used controlled decomposition of alkali and alkaline-earth metal azides at 3-12 GPa to obtain diazenides $\mathrm{Li}_{2} \mathrm{~N}_{2}, \mathrm{CaN}_{2}, \mathrm{SrN}_{2}$ and $\mathrm{BaN}_{2}{ }^{6,7}$ Diamond anvil cell techniques allowed the synthesis of a series of transition-metal compounds $\mathrm{MN}_{2}(\mathrm{M}=\mathrm{Ti}, \mathrm{Cr}$, $\mathrm{Fe}, \mathrm{Co}, \mathrm{Ni}, \mathrm{Cu}, \mathrm{Ru}, \mathrm{Rh}, \mathrm{Pd}, \mathrm{Re}, \mathrm{Os}, \mathrm{Ir}, \mathrm{Pt}$ ) at pressures $30-70$ $\mathrm{GPa}{ }^{8-17}$ Further pressure increase leads to extended nitrogen catenation and formation of various polynitrogen species such as polytetrazene $[-\mathrm{N}-\mathrm{N}-\mathrm{N}=\mathrm{N}-]_{\mathrm{n}}$ in $\mathrm{FeN}_{4}$ and $\mathrm{Hf}_{2} \mathrm{~N}_{11},{ }^{18-20}$ polyacetylene-like chains in $\mathrm{MgN}_{4},{ }^{21} \mathrm{Hf}_{4} \mathrm{~N}_{20} \cdot \mathrm{N}_{2}, \mathrm{WN}_{8} \cdot \mathrm{N}_{2}$, $\mathrm{Os}_{5} \mathrm{~N}_{28} \cdot 3 \mathrm{~N}_{2},{ }^{20} \mathrm{ReN}_{8} \cdot \mathrm{N}_{2},{ }^{22}$ pentazolate cyclo- $-\mathrm{N}_{5}$ in $\mathrm{CsN}_{5}{ }^{23}$ and $\mathrm{LiN}_{5}{ }^{24}$

In $\mathrm{MN}_{2}$ compounds metals usually possess their common oxidation states, while dinitrogen anion formally accommodates from 1 to 4 electrons. The degree of the charge transfer from metal to nitrogen significantly affects the properties of materials. For example, pernitrides of $\mathrm{Pt}, \mathrm{Ir}, \mathrm{Os}$, Ti with $\left[\mathrm{N}_{2}\right]^{4-}$ units and metals in the oxidation state IV are much more incompressible than $\mathrm{M}^{\mathrm{III}} \mathrm{N}_{2}(\mathrm{M}=\mathrm{Cr}, \mathrm{Fe}, \mathrm{Co}, \mathrm{Ni}, \mathrm{Ru}, \mathrm{Rh})$ with $\left[\mathrm{N}_{2}\right]^{3-}$, diazenides $\mathrm{M}^{\mathrm{II}} \mathrm{N}_{2}(\mathrm{M}=\mathrm{Ca}, \mathrm{Ba}, \mathrm{Sr})$ with $\left[\mathrm{N}_{2}\right]^{2-}$ and $\mathrm{M}^{\mathrm{I}} \mathrm{N}_{2}(\mathrm{M}=$ $\mathrm{Li}, \mathrm{Cu}$ ) with $\left[\mathrm{N}_{2}\right]^{-}$.

Despite a very wide range of metals with extremely different properties the stoichiometry of their compounds containing exclusively $\left[\mathrm{N}_{2}\right]^{x-}$ anions is always $\mathrm{MN}_{2}$ with the exception of recently-synthesized lithium diazenide $\mathrm{Li}_{2} \mathrm{~N}_{2} .{ }^{7}$ Here we syn ${ }^{-}$ thesize two novel compounds in the $\mathrm{Na}-\mathrm{N}$ system: $\mathrm{NaN}_{2}$ at $\sim 4 \mathrm{GPa}$ and a compound with an unusual composition
$\mathrm{Na}_{3}\left(\mathrm{~N}_{2}\right)_{4}$ at $\sim 28 \mathrm{GPa}$ containing $\left[\mathrm{N}_{2}\right]$ units with non-integer formal charge of $-0.75 . \mathrm{Na}_{3}\left(\mathrm{~N}_{2}\right)_{4}$ opens a new class of $\left[\mathrm{N}_{2}\right]-$ containing compounds with variable stoichiometry.

The most common high-pressure route to nitrogen-rich compounds is a direct reaction between metal and nitrogen in a laser-heated diamond anvil cell. However, this method has disadvantages such as inherent inhomogeneity of the reaction mixture with varying metal: nitrogen ratio across the sample. The use of azides as precursors offers a solution to this problem. Furthermore, azides provide a nitrogen-rich environment with $\mathrm{N} / \mathrm{M} \geq 3$, and this nitrogen is already activated, i.e. the activation barrier for the reaction is usually lower than in the reaction of metal with the triply bound $\mathrm{N}_{2}$ molecule.

Sodium azide $\mathrm{NaN}_{3}$ was an object of many high-pressure studies primarily due to its application as a high energy density material. Structural studies of $\mathrm{NaN}_{3}$ at high pressures are challenging since the compound loses its crystallinity on compression. There are at least three structurally characterized phases of sodium azide: $\alpha-\mathrm{NaN}_{3}(C 2 / m), \beta-\mathrm{NaN}_{3}(R-3 m)$ and $\gamma-\mathrm{NaN}_{3}$ $(I 4 / \mathrm{mcm}) .{ }^{25}$ Two high-pressure phases above 18 and $29 \mathrm{GPa}$ were observed by Zhu et al. using XRD, ${ }^{26}$ but the structures were not determined. High-pressure Raman spectroscopy studies by Eremets et al. ${ }^{27}$ suggested the transformation of azide anions to larger nitrogen clusters in compressed $\mathrm{NaN}_{3}$, however structural characterization of these transitions is missing. Based on $a b$ initio calculations Zhang et al. suggested that azide anions in compressed $\mathrm{NaN}_{3}$ would condense to hexazine $\mathrm{N}_{6}$ rings above $58 \mathrm{GPa}^{28}$ Peiris et al. ${ }^{29}$ and Holtgrewe et al. ${ }^{30}$ demonstrated that photolysis of $\mathrm{NaN}_{3}$ leads to the formation of non-crystalline products. Here we established an alternative route for synthesis of $\mathrm{Na}-\mathrm{N}$ compounds from sodium azide by infrared laser heating at high pressure in diamond anvil cells.

\section{Experimental section}

Samples preparation 
The high-pressure high-temperature behavior of $\mathrm{NaN}_{3}(99.5 \%$, Sigma-Aldrich) was studied on three samples. For single-crystal XRD studies (samples \#1 and \#2), a powder of sodium azide $\mathrm{NaN}_{3}$ was placed in a sample chamber of a BX90 diamond anvil cell equipped with Boehler-Almax type diamonds. ${ }^{31,32} \mathrm{Re}$ foil preindented to a thickness of $30 \mu \mathrm{m}$ served as a gasket. A ruby chip was placed inside the sample chamber for pressure measurement. Sample \#3 in a symmetric diamond anvil cell and with standard-cut diamonds was used for additional Raman measurements. The samples were compressed up to 26 (Sample \#1), 4 GPa (Sample \#2) and $25 \mathrm{GPa}$ (Sample \#3) and laser-heated $(\lambda=1064 \mathrm{~nm})$ using doublesided laser-heating systems of the beamlines P02.2 (Petra III, DESY, Hamburg, Germany) ${ }^{33}$, HPCAT (APS, Argonne, USA) and GSECARS (APS, Argonne, USA) respectively. No pressure-transmitting medium was used in all experiments. For samples \#1 and \#2, it was not possible to get the precise temperature of laser-heating, because the thermal radiation emitted by the sample was very weak. From the brightness of the heating spot, the temperature can be estimated to be below $1000 \mathrm{~K}$. The sample \#3 was heated up to $\sim 1900(200) \mathrm{K}$ as determined by the black body radiation fit.

\section{$X$-ray diffraction}

XRD measurements of the sample \#1 were performed at the beamline P02.2 of Petra III (DESY, Hamburg, Germany) with the X-ray beam $(\lambda=0.2891 \AA)$ focused down to $1.8 \times 2 \mu \mathrm{m}^{2}$ by a Kirkpatrick-Baez mirror system and diffraction patterns were collected on a PerkinElmer XRD 1621 flat-panel detector. XRD measurements of the sample \#2 were performed at the beamline 16ID-B (APS, Argonne, USA) with the X-ray beam $(\lambda=0.4066 \AA)$ focused down to $5 \times 5 \mu \mathrm{m}^{2}$ by a KirkpatrickBaez mirror system and diffraction patterns were collected on a Pilatus $1 \mathrm{M}$ detector. XRD measurements of the sample \#3 were performed at the beamline 13IDD (GSECARS, APS, Argonne, USA) with the X-ray beam $(\lambda=0.2952 \AA)$ focused down to $3 \times 3 \mu \mathrm{m}^{2}$ by a Kirkpatrick-Baez mirror system and diffraction patterns were collected on a Pilatus $1 \mathrm{M}$ detector $(\mathrm{CdTe})$. For the single-crystal XRD measurements samples were rotated around a vertical $\omega$-axis in a range $\pm 35^{\circ}$. The diffraction images were collected with an angular step $\Delta \omega=$ $0.5^{\circ}$ and an exposure time of $1 \mathrm{~s}$ or $2 \mathrm{~s} /$ frame. For the analysis of the single-crystal diffraction data (indexing, data integration, frame scaling and absorption correction) we used the CrysAlis ${ }^{\text {Pro }}$ software package. Specific details of the multigrain dataset analysis are given in the Supporting Information and in the Figure S1. To calibrate an instrumental model in the CrysAlis Pro software, i.e., the sample-to-detector distance, detector's origin, offsets of goniometer angles, and rotation of both X-ray beam and the detector around the instrument axis, we used a single crystal of orthoenstatite $\left(\left(\mathrm{Mg}_{1.93} \mathrm{Fe}_{0.06}\right)\left(\mathrm{Si}_{1.93}\right.\right.$, $\left.\mathrm{Al}_{0.06}\right) \mathrm{O}_{6}, P b c a$ space group, $a=8.8117(2), b=5.18320(10)$, and $c=18.2391(3) \AA)$. Using the Olex2 crystallography software package, the structures were solved with the ShelXT structure solution program ${ }^{34}$ using Intrinsic Phasing and refined with the ShelXL ${ }^{35}$ refinement package using Least Squares minimization. The powder diffraction images were integrated to powder patterns with Dioptas software. ${ }^{36}$ Le-Bail fits of the diffraction patterns were performed with the Jana2006 software. ${ }^{37}$ CSD-1999694 and CSD-1999711 contain the supplementary crystallographic data for this paper. These data can be obtained free of charge from FIZ Karlsruhe via www.ccdc.cam.ac.uk/structures"

\section{Raman spectroscopy}

Raman spectra were measured using the GSECARS Raman system with the excitation wavelength of $532 \mathrm{~nm}$. The full description of the Raman system has been published elsewhere. ${ }^{38}$

Theoretical calculations
The minimum enthalpy structures were recalculated with the norm conserving part of the PAW. ${ }^{39}$ Energy cut-off of 750-830 $\mathrm{eV}$ using the density functional theory (DFT) code CASTEP 40 and exchange-correlation functional in Perdew-Burke-Ernzerhof (PBE) approximation. ${ }^{41}$ Thirty irreducible k-points were used for electronic Brillouin zone integration and TkachenkoSchefler dispersion correction was enabled ${ }^{42}$. The Brillouin zone integrals were performed using Monkhorst- Pack grids 43 with spacings between grid points of less than $0.01 \AA^{-1}$. The structures were considered converged when the force on each atom was less than $0.002 \mathrm{eV} / \AA$ and total energy tolerance was better than $10^{-7} \mathrm{eV}$. Deviation of the stress tensor from that defined by the target pressure was less than $0.001 \mathrm{GPa}$. The phonon dispersion and phonon frequencies calculations were performed using a finite displacements method implemented in CASTEP code. ${ }^{44}$ Finite displacement phonons are calculated only at the commensurate q-points at the cost of creating a supercell. The population analysis was carried out as implemented in CASTEP. 45

\section{Results and discussion}

The laser heating of $\mathrm{NaN}_{3}$ at $26 \mathrm{GPa}$ leads to an irreversible chemical reaction that is evidenced by the changes in the optical properties of the sample (heated area becomes opaque, see inset in Figure 1a). After the heating, the pressure increased up to $\sim 28 \mathrm{GPa}$. The reaction product has a rich spotty diffraction pattern that allowed using single-crystal XRD analysis (Figure 1b, Table S1). The methodology of such multigrain analysis is described in a number of our recent publications (e.g., Ref. ${ }^{15}$ ). The diffraction pattern could be indexed with the tetragonal body-centered unit cell with $a=4.9597(16)$ and $c=$ 16.29(7) $\AA$. Successful structure solution was achieved in a space group I4 $/$ amd (No. 141) and revealed the composition of the new compound as $\mathrm{Na}_{3} \mathrm{~N}_{8}$. Full crystallographic information for this compound is provided in the Table S1 and in the supporting cif file. The expected decomposition reaction of $\mathrm{NaN}_{3}$ should result in either the release of molecular nitrogen, or in the formation of polynitrides $\mathrm{NaN}_{\mathrm{x}}$ with $x>3$ :

$$
\begin{aligned}
& 3 \mathrm{NaN}_{3} \rightarrow \mathrm{Na}_{3} \mathrm{~N}_{8}+\frac{1}{2} \mathrm{~N}_{2} \\
& \frac{3 \mathrm{x}-8}{\mathrm{x}-3} \mathrm{NaN}_{3} \rightarrow \mathrm{Na}_{3} \mathrm{~N}_{8}+\frac{1}{\mathrm{x}-3} \mathrm{NaN}_{\mathrm{x}}
\end{aligned}
$$

Experimental information on compounds $\mathrm{NaN}_{\mathrm{x}}$ with $x>3$ is limited to a Na-pentazolate framework MPF-1, which is not expected to form at high pressure due to its open zeolitic architecture. ${ }^{46}$ However, recently Steele and Oleynik predicted that sodium pentazolate $\mathrm{NaN}_{5}$ would be among thermodynamically stable phases in the Na-N system at elevated pressures. ${ }^{47}$ In order to get an insight into the mechanism of $\mathrm{NaN}_{3}$ decomposition, we have performed Raman spectroscopy measurements (Figures S2-S4). Although we could identify peaks corresponding to the nitrogen stretching vibration $\left(v_{1}=2376 \mathrm{~cm}^{-1}\right.$ at $\sim 12 \mathrm{GPa}$, Figure S2) there is an indication that some other nitrogen-containing phases may be present in the sample chamber (Figure S4). Therefore, both reactions 1 and 2 may take place. It is likely that nitrogen and products $\mathrm{NaN}_{\mathrm{x}}$ might not be well crystallized, to produce strong diffraction peaks, which would allow their unambiguous XRD identification in a mixture with $\mathrm{Na}_{3} \mathrm{~N}_{8}$. The reaction (1) is also supported by our theoretical calculations, suggesting that it is exothermic with $\Delta H=-0.261 \mathrm{eV}$ per $\mathrm{NaN}_{3}$ unit. 


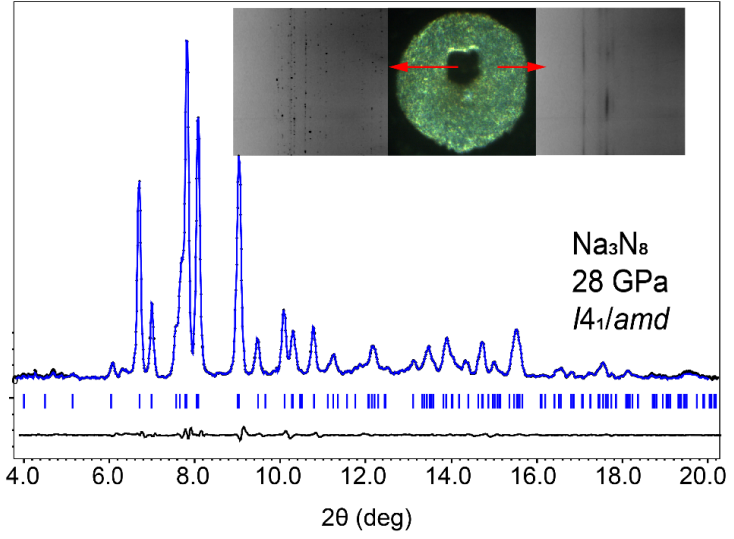

a

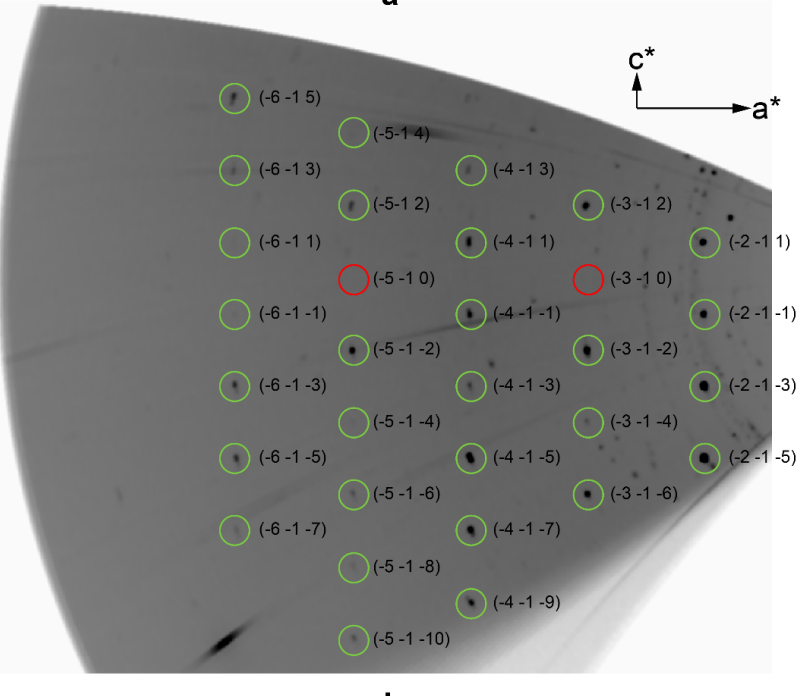

b

Figure 1. (a) Powder diffraction pattern of $\mathrm{Na}_{3} \mathrm{~N}_{8}$ at $\sim 28 \mathrm{GPa}$, $\lambda=0.2891 \AA$. Inset shows and optical image of the heated sample area at $\sim 28 \mathrm{GPa}$ and cake slices of the diffraction images of non-heated and heated sample areas (b) Reconstructed $(h-1 l)$ precession image from the single-crystal XRD dataset at $28 \mathrm{GPa}$. Reflections $h k l$ with $h+k+l=2 n+1$ are absent due to the $I$-centering of the lattice. Reflections $h k 0$ with $h=2 n+1$ or $k=2 n+1$ (marked by red circles) are absent due to the glide plane symmetry operations of the space group $14_{1} /$ amd.

$\mathrm{Na}_{3} \mathrm{~N}_{8}$ has an unprecedented structure type. However, two symmetry-independent sodium atoms $\mathrm{Na} 1$ and $\mathrm{Na} 2$ occupying Wyckoff sites $4 a$ and $8 e$ respectively form a substructure isostructural to $\alpha-\mathrm{ThSi}_{2}$ (Figure 2a). Each Na2 atom has three close $\mathrm{Na} 2$ neighbors with $d(\mathrm{Na}-\mathrm{Na})=2.81$ and $2.78 \AA$ at 28 $\mathrm{GPa}$. These distances are close to those in $b c c-\mathrm{Na}$ at similar pressures $(2.79 \AA) .{ }^{48}$ With Na2-Na2-Na2 angles close to $120^{\circ}$, $\mathrm{Na} 2$ atoms form one of the basic 3-connected three-dimensional nets (ths) described by a vertex symbol $10_{2} 10_{4} 10_{4}{ }^{49}$ Two nitrogen atoms N1 and N2 occupy Wyckoff sites $16 h$ an $16 f$ respectively and form $\mathrm{N} 1-\mathrm{N} 1$ and $\mathrm{N} 2-\mathrm{N} 2$ dinitrogen dumbbells with $d(\mathrm{~N} 1-\mathrm{N} 1)=1.147(3) \AA$ and $d(\mathrm{~N} 2-\mathrm{N} 2)=$ $1.149(3) \AA$ at $28 \mathrm{GPa}$. N1-N1 units are surrounded by seven sodium atoms forming a distorted pentagonal bipyramid as shown in the Figures $2 b-2 d$, while N2-N2 units are surrounded by six sodium atoms that form a distorted octahedron. Na1 atoms are coordinated by eight $\mathrm{N}_{2}$ units in a side-on manner, while $\mathrm{Na} 2$ - by eight end-on $\mathrm{N}_{2}$ and one side-on $\mathrm{N}_{2}$ units. Side-on coordination usually leads to a greater charge transfer${ }^{50}$, which is in a good agreement with our calculations of Mulliken atomic charges (Table S2).
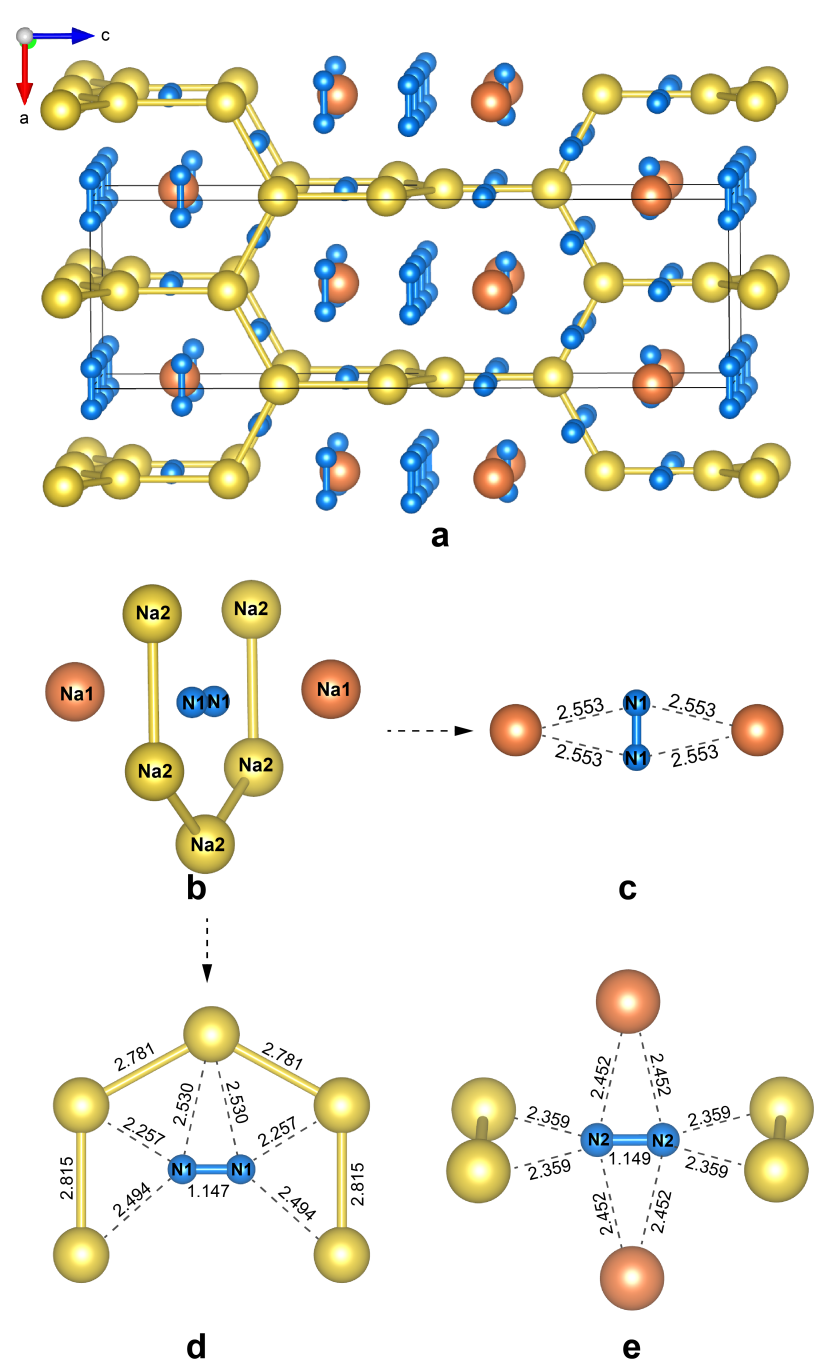

Figure 2. (a) Crystal structure of $\mathrm{Na}_{3} \mathrm{~N}_{8}$ at $28 \mathrm{GPa}$. Shortest Na$\mathrm{Na}$ contacts are indicated by yellow sticks (b)-(e) Coordination environments of nitrogen molecules.

To study the stability region of $\mathrm{Na}_{3} \mathrm{~N}_{8}$ the sample was decompressed in a few steps to ambient pressure. $\mathrm{Na}_{3} \mathrm{~N}_{8}$ remains in the sample chamber down to $7.7 \mathrm{GPa}$. Lattice parameters increase with decreasing pressure with $c / a$ ratio approaching, but not reaching, the ideal value for the ths net of $2 \sqrt{3}$. One can notice a slight kink in the pressure-dependence of the unit cell parameters $a$ and $c$ at $\sim 15 \mathrm{GPa}$ (Figure S5). We should note here that while the experiment was performed under very nonhydrostatic conditions the evolution of deviatoric stresses may influence the behavior of the lattice parameters on compression or decompression. Furthermore, the certain systematic error in pressure determination may occur due to the pressure gradient between the pressure marker (ruby) and the heated spot. However, we should also mention that the refined N1-N1 and N2-N2 distances that are similar above $15 \mathrm{GPa}$, begin to deviate at lower pressures (Figure S5). The N2-N2 distance unexpectedly decreases with decreasing pressure and tends to the N-N distance in triply bound dinitrogen molecule. This may indicate the onset of charge redistribution between two dinitrogen units and an onset of further decomposition. 


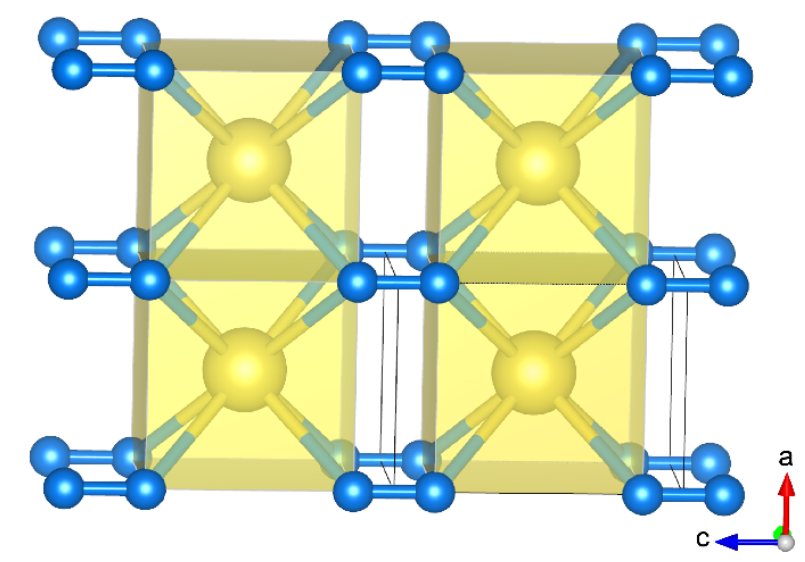

Figure 3. Crystal structure of $\mathrm{NaN}_{2}$ at $4 \mathrm{GPa}$. Nitrogen and sodium atoms shown as blue and yellow spheres, respectively. $\mathrm{NaN}_{8}$ coordination polyhedra are highlighted. $d(\mathrm{~N}-\mathrm{N})=1.161(9) \AA$, $d(\mathrm{Na}-\mathrm{N})=2.582(3) \AA$.

Further decompression to $4 \mathrm{GPa}$ resulted in the disappearance of all single-crystalline spots in the diffraction pattern and in the formation of a powder-like sample. Primitive tetragonal unit cell with $a=3.0009(13)$ and $c=4.101(3) \AA$ describes the positions of the diffraction peaks with a good agreement (Figure S6). To recrystallize this compound, the sample was slightly heated by the infrared laser $(\lambda=1064 \mathrm{~nm})$, which allowed the analysis of the crystal structure by means of single-crystal $\mathrm{X}$-ray diffraction. Structure solution and refinement revealed the composition of this compound as $\mathrm{NaN}_{2}$ (Table $\mathrm{S} 1$ ). $\mathrm{NaN}_{2}$ is isostructural to $\alpha-\mathrm{FeSi}_{2}$ and has a space group $\mathrm{P} 4 / \mathrm{mmm}$ (No. 123). It can be described as a layer packing structure, in which the layers are stacked along [001]. The layers consisting of face-sharing $\mathrm{NaN}_{8}$ slightly distorted cubes are interconnected through N-N bonds with $d(\mathrm{NN})=1.161(9) \AA$ at $4 \mathrm{GPa}$ (Figure 3). Powder-like $\mathrm{NaN}_{2}$ was also obtained in a separate experiment by heating sodium azide compressed at $4.5 \mathrm{GPa}$ (Figure S6). On decompression $\mathrm{NaN}_{2}$ is stable down to at least 2.8 $\mathrm{GPa}$ but decomposes with the formation of $b c c-\mathrm{Na}$ at ambient pressure (Figure S6).

Both $\mathrm{Na}_{3} \mathrm{~N}_{8}$ and $\mathrm{NaN}_{2}$ have very unusual electron counts. The chemical formula of $\mathrm{Na}_{3} \mathrm{~N}_{8}$ can be rewritten as $\mathrm{Na}_{3}\left(\mathrm{~N}_{2}\right)_{4}$ and if we assume that $\mathrm{Na}$ is in its standard oxidation state $+\mathrm{I}$, the charge on each dinitrogen unit would be -0.75 . Obviously, 0.75 electrons cannot be localized on the nitrogen antibonding $\pi^{*}$ orbitals and these electrons must be either delocalized, or the compound may be an electride $\mathrm{Na}_{3}{ }_{3}\left(\mathrm{~N}_{2}\right)_{4} \cdot 3 e$, with electrons serving as anions like in some subnitrides $\left(\right.$ e.g. $\left[\mathrm{Ca}_{2} \mathrm{~N}\right]$ $\left.+\cdot e^{-}\right) .{ }^{51}$ A more unlikely scenario is that $\mathrm{Na}_{3} \mathrm{~N}_{8}$ is a van der Waals compound without a charge transfer from sodium to nitrogen atoms. Similar considerations are valid for $\mathrm{NaN}_{2}$ too. The first clue on the bonding situation comes from the analysis of interatomic nitrogen-nitrogen distances. Assuming the complete charge transfer from sodium to nitrogen atoms, the $\mathrm{N}-\mathrm{N}$ bond orders in $\mathrm{Na}_{3} \mathrm{~N}_{8}$ and $\mathrm{NaN}_{2}$ should be 2.625 and 2.5, respectively. Therefore, in this case $\mathrm{N}-\mathrm{N}$ distances should be only slightly longer than the triple $\mathrm{N} \equiv \mathrm{N}$ bond.

Indeed, the interatomic nitrogen-nitrogen distances in $\mathrm{Na}_{3} \mathrm{~N}_{8}$ and in $\mathrm{NaN}_{2}$ (1.147 and $1.161 \AA$ ) are in a very good agreement with the formal N-N bond orders and clearly follow the trend $d_{\mathrm{NN}}(\mathrm{N} \equiv \mathrm{N})<d_{\mathrm{NN}}\left(\mathrm{Na}_{3} \mathrm{~N}_{8}\right)<d_{\mathrm{NN}}\left(\mathrm{NaN}_{2}\right)<d_{N N}($ diazenides $)<$ $d_{\mathrm{NN}}$ (pernitrides). We note here that $\mathrm{N}-\mathrm{N}$ dimers are very incompressible. For instance the N-N single bond length variation in $\mathrm{ReN}_{2}$ between 0 and $42 \mathrm{GPa}$ is about $0.05 \AA 15$, while higher-order N-N bonds are expected to be even more incompressible. Therefore, for qualitative purposes, it is justified to compare N-N distances in compounds at slightly different pressures. The elongation of N-N distances in $\mathrm{Na}_{3} \mathrm{~N}_{8}$ and in $\mathrm{NaN}_{2}$ compared to $\mathrm{N} \equiv \mathrm{N}$ suggests that charge transfer occurs in both compounds and the electrons are delocalized between nitrogen $p$-states, implying the metallic character of both compounds, which agrees with the observed black metallic color of the samples. In order to get a deeper insight into the bonding nature, we have performed electronic structure calculations that confirmed that both compounds are metallic (Figure 4) and the main contributions of bands at the Fermi level comes from the $\mathrm{N} 2 p$ states.

Hitherto, several uncommon diazenides such as $\left(\mathrm{Sr}^{2+}\right)_{8}\left(\mathrm{~N}^{3-}\right)_{4}\left(\left[\mathrm{~N}_{2}\right]^{2-}\right) \cdot 2 e^{-}$or $\left(\mathrm{Li}^{+}\right)_{2}\left(\mathrm{Ca}^{2+}\right)_{3}\left(\left[\mathrm{~N}_{2}\right]^{2-}\right)_{3} \cdot 3 e^{-}$were synthesized at high-pressure conditions. 52,53 These compounds contain diazenide anions $\left[\mathrm{N}_{2}\right]^{2-}$ and the delocalized electrons responsible for their metallic properties. By analogy with subnitrides such as $\left(\mathrm{Ba}^{2+}\right)_{3}\left(\mathrm{~N}^{3-}\right) \cdot 3 e$, these compounds were called subdiazenides. On the contrary, both $\mathrm{NaN}_{2}$ and $\mathrm{Na}_{3} \mathrm{~N}_{8}$ may be considered as undercharged diazenides. Dinitrides with undercharged diazenide anions $\left[\mathrm{N}_{2}\right]^{-}$were recently reported in $\mathrm{Li}-\mathrm{N}$ and $\mathrm{Cu}-\mathrm{N}$ systems. Laniel et al. synthesized $\mathrm{LiN}_{2}$ in a reaction between $\mathrm{Li}_{3} \mathrm{~N}$ and nitrogen at $10.5 \mathrm{GPa}$, while $\mathrm{CuN}_{2}$ was synthesized from elements at $\sim 50 \mathrm{GPa} .{ }^{10}$ Both compounds have hexagonal NiAs $P 6_{3} / m m c$ structure type with $\mathrm{N}-\mathrm{N}$ distances of $\sim 1.2 \AA$. Undercharged $\left[\mathrm{N}_{2}\right]$ - diazenide groups are also present in $\mathrm{Hf}_{2} \mathrm{~N}_{11}$ compound synthesized at 1 Mbar. ${ }^{20}$ 


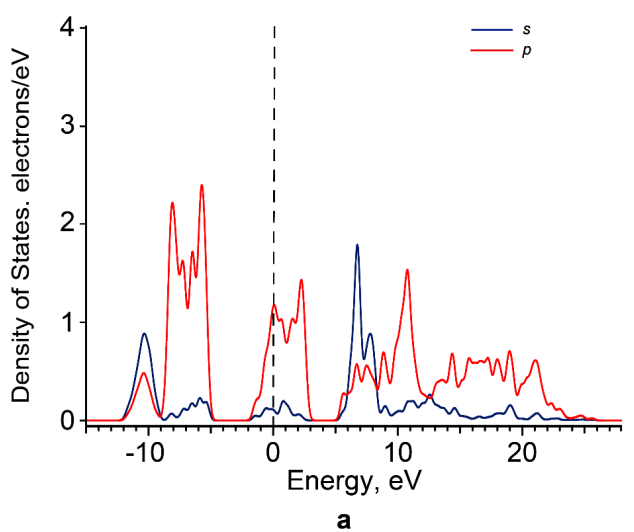

a

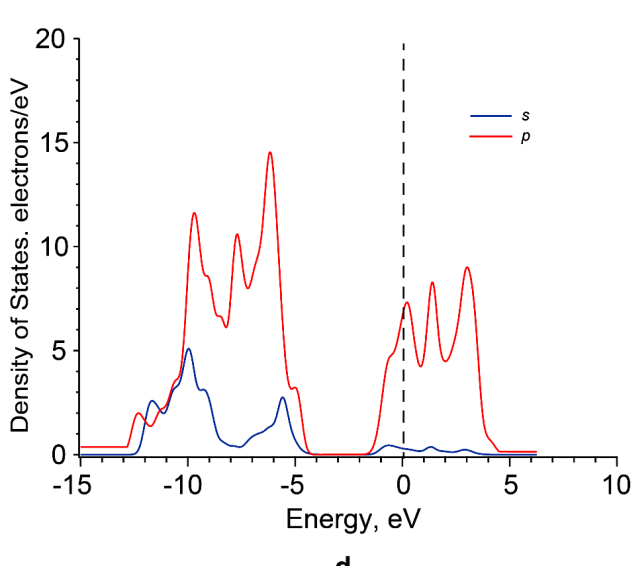

d

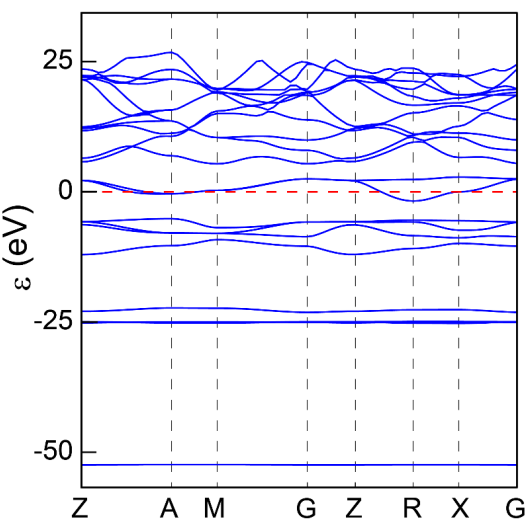

b

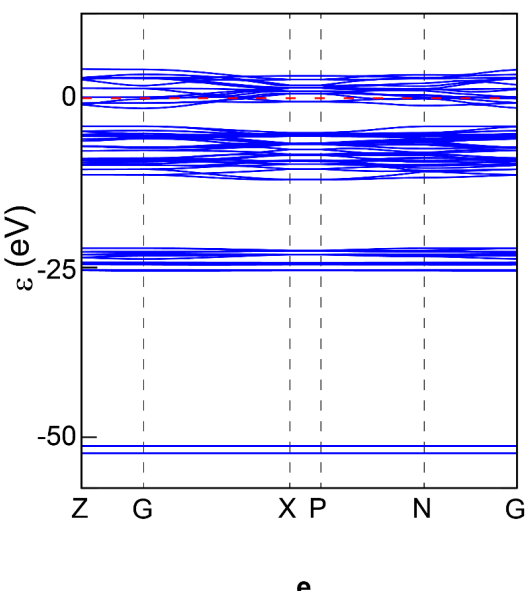

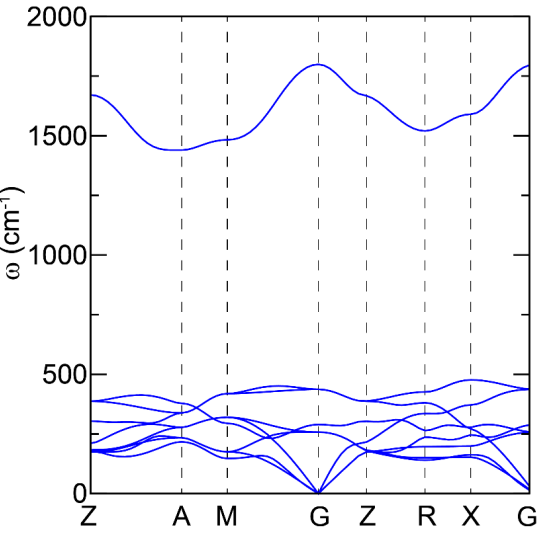

c

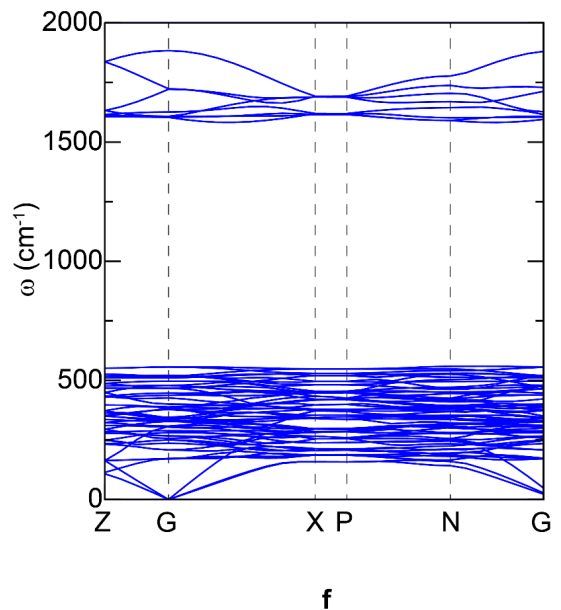

Figure 4. (a) Electron density of states, (b) band structure, and (c) phonon dispersion of $\mathrm{NaN}_{2}$ at 4 GPa. (d) Electron density of states, (e) band structure, and (f) phonon dispersion of $\mathrm{Na}_{3} \mathrm{~N}_{8}$ at $28 \mathrm{GPa}$.

An unprecedented example of $\mathrm{Na}_{3} \mathrm{~N}_{8}$ demonstrates that $\left[\mathrm{N}_{2}\right]$ units with non-integer formal charge exist. The $\left[\mathrm{N}_{2}\right]$ unit may therefore serve as a versatile electron acceptor in solid-state chemistry and may exist not only in compounds with simple $\mathrm{AB}_{2}$ or $\mathrm{A}_{2} \mathrm{~B}_{2}$ stoichiometries.

Phonon dispersion calculations show that $\mathrm{Na}_{3} \mathrm{~N}_{8}$ is dynamically stable at $28 \mathrm{GPa}$ (Figure 4), but it becomes unstable at lower pressures as indicated by the appearance of imaginary phonon frequencies near the Z-point (Figure S7), which agrees with our experimental findings. We have also constructed a part of the convex hull diagram, showing the relative stabilities of the experimental $\mathrm{Na}-\mathrm{N}$ phases in the vicinity of $\mathrm{N}: \mathrm{Na}$ ratio 3:1 (Figure S8). At low pressure (4 GPa), $P 4 / m m m ~ \mathrm{NaN}_{2}$ phase is dynamically and thermodynamically stable. Interestingly, the most common $\mathrm{Na}-\mathrm{N}$ phase $\mathrm{NaN}_{3}$ emerges here as the least stable phase. At the first glance this seems counterintuitive, but in fact this compound is a metastable phase at standard conditions too: it has positive standard Gibbs free energy of formation $\Delta_{\mathrm{f}} G^{\mathrm{o}}=93.7 \mathrm{~kJ} / \mathrm{mol}^{54} \mathrm{NaN}_{3}$ is kinetically stable at ambient conditions with an activation barrier of $\sim 150 \mathrm{~kJ} / \mathrm{mol}$ for its decomposition reaction that requires breaking nitrogennitrogen bonds in the azide anion.55 The decomposition of $\mathrm{NaN}_{2}$ does not have this requirement and we can assume that the activation barrier of $\mathrm{NaN}_{2}$ decomposition is substantially lower than that of $\mathrm{NaN}_{3}$. That is why $\mathrm{NaN}_{2}$ could not be preserved at ambient conditions but leaves a room for its lowtemperature kinetic stabilization.

The formation of $\mathrm{NaN}_{2}$ also agrees with the theoretical studies of Steele and Oleynik, who predicted $P 4 / \mathrm{mmm} \mathrm{NaN} 2$ in the
$\mathrm{Na}-\mathrm{N}$ system. ${ }^{47}$ Our calculation of the convex hull diagram at $28 \mathrm{GPa}$ shows that $\mathrm{NaN}_{2}$ with $\mathrm{Cmmm}$ symmetry emerges as the thermodynamically stable phase (in agreement with Ref. ${ }^{47}$ ), while $\mathrm{Na}_{3} \mathrm{~N}_{8}$ is slightly metastable (but is on the hull within the accuracy of the calculations). The calculations of Steele and Oleynik considered $\mathrm{Na}_{\mathrm{x}} \mathrm{N}_{\mathrm{y}}$ structures having up to 16 atoms in the unit cell and this could explain why $\mathrm{Na}_{3} \mathrm{~N}_{8}$, containing 44 atoms in the unit cell (22 atoms in the primitive cell) was not predicted. The existence of $\mathrm{Na}_{3} \mathrm{~N}_{8}$ may have a consequence on the calculated stability regions of predicted $\mathrm{NaN}_{5}$, and $\mathrm{Na}_{2} \mathrm{~N}_{5}$ compounds. ${ }^{47}$

\section{Conclusions}

To conclude, in this study we discovered that pressure-temperature induced decomposition of sodium azide $\mathrm{NaN}_{3}$ leads to two novel compounds $\mathrm{Na}_{3} \mathrm{~N}_{8}$ and $\mathrm{NaN}_{2}$. The studied reaction flow can be summarized by Scheme 1:

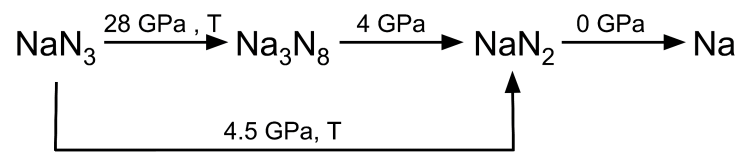

Scheme 1. Summary of pressure-temperature induced reactions in the Na-N system studied in this communication.

The dinitrogen units in $\mathrm{NaN}_{2}$ and $\mathrm{Na}_{3} \mathrm{~N}_{8}$ have formal charges of -1 and -0.75 respectively. $\mathrm{N}_{2}$ unit is therefore the unique structural species that can accommodate a range of possible 
formal charges including non-integer ones. This opens a new class of solid-state compounds containing homonuclear dinitrogen anions and having various compositions. It is likely that compounds with $\mathrm{M}_{3} \mathrm{~N}_{8}$ stoichiometry may be found for group 2 metals with similar ionic radii as $\mathrm{Na}^{+}$(especially $\mathrm{Ca}$ and $\mathrm{Sr}$ ). Replacing $\mathrm{Na}$ by the alkaline-earth metal in $\mathrm{Na}_{3} \mathrm{~N}_{8}$ would lead to compounds $\mathrm{M}_{3} \mathrm{~N}_{8} \mathrm{~N}_{8}$ with $\left[\mathrm{N}_{2}\right]^{1.5-}$.

Azides and $\mathrm{NaN}_{3}$ in particular are often used in a synthesis of nitrides, $56-60$ where they are commonly considered as solid sources of nitrogen, taking in account their ambient-pressure decomposition route $\left(2 \mathrm{NaN}_{3} \rightarrow 2 \mathrm{Na}+3 \mathrm{~N}_{2}\right)$. Our study shows that sodium azide can be already decomposed at $4 \mathrm{GPa}$, which results in the formation of activated $\left[\mathrm{N}_{2}\right]^{-}$species together with molecular $\mathrm{N}_{2}$ and this mechanism may play a crucial role for the high-pressure solid-state metathesis synthetic approach that recently became widespread for the synthesis of nitrides. ${ }^{61-63}$ The formation of stable $\mathrm{Na}_{3} \mathrm{~N}_{8}$ compound with a very unexpected stoichiometry is an important indication that theoretical calculations, which became widespread in the highpressure community 64,65 should always include variable-stoichiometry search and should not limit the unit cell contents to a few atoms for the sake of the computation time. Therefore, these experiments revealing unexpected compositions are an important contribution for the adjustments of computational strategies.

\section{ASSOCIATED CONTENT}

\section{Supporting Information.}

Crystallographic information files for $\mathrm{Na}_{3} \mathrm{~N}_{8}$ and $\mathrm{NaN}_{2}$. Details of structure refinement, powder diffraction patterns, Raman spectra. This material is available free of charge via the Internet at http:// pubs.acs.org.

\section{AUTHOR INFORMATION}

\section{Corresponding Author}

* Maxim Bykov.maks.byk@gmail.com

\section{Author Contributions}

The manuscript was written through contributions of all authors. All authors have given approval to the final version of the manuscript.

\section{Funding Sources}

Research was sponsored by the Army Research Office and was accomplished under the Cooperative Agreement Number W911NF-19-2-0172.

\section{ACKNOWLEDGMENT}

Parts of this research were carried out at the Extreme Conditions Beamline (P02.2) at DESY, a member of Helmholtz Association (HGF). Portions of this work were performed at HPCAT (Sector 16), Advanced Photon Source (APS), Argonne National Laboratory. HPCAT operations are supported by DOE-NNSA's Office of Experimental Sciences. Raman spectroscopy experiments were performed at GeoSoilEnviroCARS (The University of Chicago, Sector 13), Advanced Photon Source (APS), Argonne National Laboratory. GeoSoilEnviroCARS is supported by the National Science Foundation - Earth Sciences (EAR - 1634415) and Department of Energy- GeoSciences (DE-FG02-94ER14466). The Advanced Photon Source is a U.S. Department of Energy (DOE) Office of Science User Facility operated for the DOE Office of Science by Argonne National Laboratory under Contract No. DEAC02-06CH11357.

\section{ABBREVIATIONS}

$\mathrm{XRD}, \mathrm{X}$-ray diffraction; DAC, diamond anvil cell

\section{REFERENCES}

(1) Shaver, M. P.; Fryzuk, M. D. Activation of Molecular Nitrogen: Coordination, Cleavage and Functionalization of N2 Mediated By Metal Complexes. Adv. Synth. Catal. 2003, 345 (910), 10611076. https://doi.org/10.1002/adsc.200303081.

(2) Crossland, J. L.; Tyler, D. R. Iron-Dinitrogen Coordination Chemistry: Dinitrogen Activation and Reactivity. Coord. Chem Rev. 2010, 254 (17-18), 1883-1894. https://doi.org/10.1016/ j.ccr.2010.01.005.

(3) Yandulov, D. V.; Schrock, R. R. Catalytic Reduction of Dinitrogen to Ammonia at a Single Molybdenum Center. Science 2003, 301 (5629), 76-78. https://doi.org/10.1126/science.1085326.

(4) Auffermann, G.; Prots, Y.; Kniep, R. SrN and SrN2: Diazenides by Synthesis under High N2-Pressure. Angew. Chemie Int. Ed. 2001,40 (3), $547-549$. h t tp s://doi.org/ $10.1002 / 1521-3773(20010202) 40: 3<547:$ :AID ANIE547>3.0.CO;2-X.

(5) Vajenine, G. V.; Auffermann, G.; Prots, Y.; Schnelle, W.; Kremer, R. K.; Simon, A.; Kniep, R. Preparation, Crystal Structure, and Properties of Barium Pernitride, BaN2. Inorg. Chem. 2001, 40 (19), 4866-4870. https://doi.org/10.1021/IC010263+.

(6) Schneider, S. B.; Frankovsky, R.; Schnick, W. Synthesis of Alkaline Earth Diazenides $\mathrm{M}_{\mathrm{AE}} \mathrm{N}_{2}\left(\mathrm{M}_{\mathrm{AE}}=\mathrm{Ca}, \mathrm{Sr}, \mathrm{Ba}\right)$ by Controlled Thermal Decomposition of Azides under High Pressure. Inorg. Chem. 2012, 51 (4), 2366-2373. https://doi.org/10.1021/ ic2023677.

(7) Schneider, S. B.; Frankovsky, R.; Schnick, W. High-Pressure Synthesis and Characterization of the Alkali Diazenide $\mathrm{Li}_{2} \mathrm{~N}_{2}$ Angew. Chemie Int. Ed. 2012, 51 (8), 1873-1875. https:// doi.org/10.1002/anie.201108252.

Bhadram, V. S.; Kim, D. Y.; Strobel, T. A. High-Pressure Synthesis and Characterization of Incompressible Titanium Pernitri. de. Chem. Mater. 2016, 28 (6), 1616-1620. https://doi.org/ 10.1021/acs.chemmater.6b00042.

(9) Niwa, K.; Fukui, R.; Terabe, T.; Kawada, T.; Kato, D.; Sasaki, T.; Soda, K.; Hasegawa, M. High-Pressure Synthesis and Phase Stability of Nickel Pernitride. Eur. J. Inorg. Chem. 2019, 2019 (33), 3753-3757. https://doi.org/10.1002/ejic.201900489.

(10) Binns, J.; Donnelly, M. E.; Pena-Alvarez, M.; Wang, M.; Gregoryanz, E.; Hermann, A.; Dalladay-Simpson, P.; Howie, R. T. Direct Reaction between Copper and Nitrogen at High Pressures and Temperatures. J. Phys. Chem. Lett. 2019, 10 (5), 1109-1114. https://doi.org/10.1021/acs.jpclett.9b00070.

(11) Niwa, K.; Suzuki, K.; Muto, S.; Tatsumi, K.; Soda, K.; Kikegawa, T.; Hasegawa, M. Discovery of the Last Remaining Binary Platinum-Group Pernitride $\mathrm{RuN}_{2}$. Chem. - A Eur. J. 2014, 20 (43), 13885-13888. https://doi.org/10.1002/chem.201404165.

(12) Niwa, K.; Dzivenko, D.; Suzuki, K.; Riedel, R.; Troyan, I.; Eremets, M.; Hasegawa, M. High Pressure Synthesis of Marcasite-Type Rhodium Pernitride. Inorg. Chem. 2014, 53 (2), $697-$ 699. https://doi.org/10.1021/ic402885k.

(13) Bykov, M.; Yusenko, K. V.; Bykova, E.; Pakhomova, A.; Kraus, W.; Dubrovinskaia, N.; Dubrovinsky, L. Synthesis of Arsenopyrite-Type Rhodium Pernitride RhN 2 from a Single-Source Azide Precursor. Eur. J. Inorg. Chem. 2019, 2019 (32), 3667-3671. https://doi.org/10.1002/ejic.201900488.

(14) Crowhurst, J. C.; Goncharov, A. F.; Sadigh, B.; Zaug, J. M.; Aberg, D.; Meng, Y.; Prakapenka, V. B. Synthesis and Characterization of Nitrides of Iridium and Palladium. J. Mater. Res. 2008, 23 (01), 1-5. https://doi.org/10.1557/JMR.2008.0027.

(15) Bykov, M.; Chariton, S.; Fei, H.; Fedotenko, T.; Aprilis, G.; Ponomareva, A. V.; Tasnádi, F.; Abrikosov, I. A.; Merle, B.; Feldner, P.; et al. High-Pressure Synthesis of Ultraincompressible Hard Rhenium Nitride Pernitride Re2(N2)(N)2 Stable at Ambient Conditions. Nat. Commun. 2019, 10 (1), 2994. https:// doi.org/10.1038/s41467-019-10995-3.

(16) Crowhurst, J. C.; Goncharov, A. F.; Sadigh, B.; Evans, C. L.; Morral, P. G.; Ferreira, J. L.; Nelson, A. J. Synthesis and Characterization of the Nitrides of Platinum and Iridium. Science 2006, 311 (5765), 1275-1278. https://doi.org/10.1126/ science. 1121813 .

(17) Young, A. F.; Sanloup, C.; Gregoryanz, E.; Scandolo, S.; Hemley, R. J.; Mao, H. Synthesis of Novel Transition Metal Nitrides $\mathrm{IrN}_{2}$ and $\mathrm{OsN}_{2}$. Phys. Rev. Lett. 2006, 96 (15), 155501. https:// doi.org/10.1103/PhysRevLett.96.155501.

(18) Bykov, M.; Bykova, E.; Aprilis, G.; Glazyrin, K.; Koemets, E.; Chuvashova, I.; Kupenko, I.; McCammon, C.; Mezouar, M.; 
Prakapenka, V.; et al. Fe-N System at High Pressure Reveals a Compound Featuring Polymeric Nitrogen Chains. Nat. Commun. 2018, 9 (1), 2756. https://doi.org/10.1038/ s41467-018-05143-2.

(19) Bykov, M.; Khandarkhaeva, S.; Fedotenko, T.; Sedmak, P. Dubrovinskaia, N.; Dubrovinsky, L. Synthesis of FeN 4 at 180 GPa and Its Crystal Structure from a Submicron-Sized Grain. Acta Crystallogr. Sect. E Crystallogr. Commun. 2018, 74, 13921395. https://doi.org/10.1107/S2056989018012161.

(20) Bykov, M.; Chariton, S.; Bykova, E.; Khandarkhaeva, S.; Fedotenko, T.; Ponomareva, A. V.; Tidholm, J.; Tasnádi, F.; Abriko. sov, I. A.; Sedmak, P.; et al. High-Pressure Synthesis of MetalInorganic Frameworks Hf $4 \mathrm{~N} 20 \cdot \mathrm{N} 2$, WN $8 \cdot \mathrm{N} 2$, and Os $5 \mathrm{~N}$ $28 \cdot 3 \mathrm{~N} 2$ with Polymeric Nitrogen Linkers. Angew. Chemie Int. Ed. 2020, 59 (26), 10321-10326. https://doi.org/10.1002/ anie. 202002487

(21) Laniel, D.; Winkler, B.; Koemets, E.; Fedotenko, T.; Bykov, M.; Bykova, E.; Dubrovinsky, L.; Dubrovinskaia, N. Synthesis of Magnesium-Nitrogen Salts of Polynitrogen Anions. Nat. Com mun. 2019, 10 (1), 4515. https://doi.org/10.1038/ s41467-019-12530-w.

(22) Bykov, M.; Bykova, E.; Koemets, E.; Fedotenko, T.; Aprilis, G.; Glazyrin, K.; Liermann, H.-P.; Ponomareva, A. V.; Tidholm, J.; Tasnádi, F.; et al. High-Pressure Synthesis of a Nitrogen-Rich Inclusion Compound ReN8·xN2 with Conjugated Polymeric Nitrogen Chains. Angew. Chemie Int. Ed. 2018, 57 (29), 90489053. https://doi.org/10.1002/anie.201805152.

(23) Steele, B. A.; Stavrou, E.; Crowhurst, J. C.; Zaug, J. M.; Prakapenka, V. B.; Oleynik, I. I. High-Pressure Synthesis of a Pentazolate Salt. Chem. Mater. 2017, 29 (2), 735-741. https://doi.org/ 10.1021/acs.chemmater.6b04538.

(24) Laniel, D.; Weck, G.; Gaiffe, G.; Garbarino, G.; Loubeyre, P. High-Pressure Synthesized Lithium Pentazolate Compound Metastable under Ambient Conditions. J. Phys. Chem. Lett. 2018, 9 (7), 1600-1604. https://doi.org/10.1021/ acs.jpclett.8b00540.

(25) Pulham; Millar; Barry; Marshall. Structural Characterization of Sodium Azide and Sodium Bifluoride at High Pressures. Zeit. schrift für Krist. Cryst. Mater. 2014, 229 (3), 259-275. https:// doi.org/10.1515/zkri-2013-1660.

(26) Zhu, H.; Zhang, F.; Ji, C.; Hou, D.; Wu, J.; Hannon, T.; Ma, Y. Pressure-Induced Series of Phase Transitions in Sodium Azide Pressure-Induced Series of Phase Transitions in Sodium Azide. J. Appl. Phys. 2016, 113 (2013), 033511. https://doi.org/ 10.1063/1.4776235.

(27) Eremets, M. I.; Popov, M. Y.; Trojan, I. A.; Denisov, V. N.; Boehler, R.; Hemley, R. J. Polymerization of Nitrogen in Sodi_ um Azide. J. Chem. Phys. 2004, 120 (22), 10618-10623. https:// doi.org/10.1063/1.1718250.

(28) Zhang, M.; Yin, K.; Zhang, X.; Wang, H.; Li, Q.; Wu, Z. Structural and Electronic Properties of Sodium Azide at High Pressure: A First Principles Study. Solid State Commun. 2013, 161, 1318. https://doi.org/10.1016/j.ssc.2013.01.032.

(29) Peiris, S. M.; Russell, T. P. Photolysis of Compressed Sodium Azide (NaN 3 ) as a Synthetic Pathway to Nitrogen Materials. $J$. Phys. Chem. A 2003, 107 (6), 944-947. https://doi.org/10.1021/ jp025963u.

(30) Holtgrewe, N.; Lobanov, S. S.; Mahmood, M. F.; Goncharov, A. F. Photochemistry within Compressed Sodium Azide. J. Phys. Chem. C 2016, 120 (49), 28176-28185. https://doi.org/10.1021/ acs.jpcc.6b09103.

(31) Kantor, I.; Prakapenka, V.; Kantor, A.; Dera, P.; Kurnosov, A.; Sinogeikin, S.; Dubrovinskaia, N.; Dubrovinsky, L. BX90: A New Diamond Anvil Cell Design for X-Ray Diffraction and Optical Measurements. Rev. Sci. Instrum. 2012, 83 (12), 125102. https://doi.org/10.1063/1.4768541.

(32) Boehler, R. New Diamond Cell for Single-Crystal x-Ray Diffraction. Rev. Sci. Instrum. 2006, 77 (11), 115103. https:// doi.org/10.1063/1.2372734.

(33) Liermann, H.-P.; Konôpková, Z.; Morgenroth, W.; Glazyrin, K.; Bednarčik, J.; McBride, E. E.; Petitgirard, S.; Delitz, J. T.; Wendt, M.; Bican, Y.; et al. The Extreme Conditions Beamline P02.2 and the Extreme Conditions Science Infrastructure at PETRA III. J. Synchrotron Radiat. 2015, 22 (4), 908-924. https://doi.org/10.1107/S1600577515005937.

(34) Sheldrick, G. M. SHELXT - Integrated Space-Group and Crystal-Structure Determination. Acta Crystallogr. Sect. A Found. $A d v .2015,71$ (1), 3-8. https://doi.org/10.1107/
S2053273314026370.

Sheldrick, G. M. Crystal Structure Refinement with SHELXL. Acta Crystallogr. Sect. C Struct. Chem. 2015, 71 (1), 3-8. https://doi.org/10.1107/S2053229614024218.

(36) Prescher, C.; Prakapenka, V. B. DIOPTAS: A Program for Reduction of Two-Dimensional X-Ray Diffraction Data and Data Exploration. High Press. Res. 2015, 35 (3), 223-230. https:// doi.org/10.1080/08957959.2015.1059835.

(37) Petricek, V.; Dusek, M.; Palatinus, L. Crystallographic Computing System JANA2006: General Features. Zeitschrift für Krist. 2014, 229 (5), 345-352.

(38) Holtgrewe, N.; Greenberg, E.; Prescher, C.; Prakapenka, V. B.; Goncharov, A. F. Advanced Integrated Optical Spectroscopy System for Diamond Anvil Cell Studies at GSECARS. High Press. Res. 2019, 39 (3), 457-470. https://doi.org/ 10.1080/08957959.2019.1647536.

(39) Hamann, D. R.; Schlüter, M.; Chiang, C. Norm-Conserving Pseudopotentials. Phys. Rev. Lett. 1979, 43 (20), 1494-1497. https://doi.org/10.1103/PhysRevLett.43.1494.

(40) Segall, M. D.; Lindan, P. J. D.; Probert, M. J.; Pickard, C. J.; Hasnip, P. J.; Clark, S. J.; Payne, M. C. First-Principles Simulation: Ideas, Illustrations and the CASTEP Code. J. Phys. Condens. Matter 2002, 14 (11), 2717-2744. https://doi.org/ 10.1088/0953-8984/14/11/301.

(41) Perdew, J. P.; Burke, K.; Ernzerhof, M. Generalized Gradient Approximation Made Simple. Phys. Rev. Lett. 1996, 77 (18), 3865-3868. https://doi.org/10.1103/PhysRevLett.77.3865.

(42) Tkatchenko, A.; Scheffler, M. Accurate Molecular Van Der Waals Interactions from Ground-State Electron Density and Free-Atom Reference Data. Phys. Rev. Lett. 2009, 102 (7), 073005. https://doi.org/10.1103/PhysRevLett.102.073005.

(43) Monkhorst, H. J.; Pack, J. D. Special Points for Brillouin-Zone Integrations. Phys. Rev. B 1976, 13 (12), 5188-5192. https:// doi.org/10.1103/PhysRevB.13.5188.

(44) Refson, K.; Tulip, P. R.; Clark, S. J. Variational Density-Functional Perturbation Theory for Dielectrics and Lattice Dynamics. Phys. Rev. B 2006, 73 (15), 155114. https://doi.org/10.1103/ PhysRevB.73.155114

(45) Segall, M. D.; Pickard, C. J.; Shah, R.; Payne, M. C. Population Analysis in Plane Wave Electronic Structure Calculations. Mol. Phys. 1996, 89 (2), 571-577. https://doi.org/ $10.1080 / 002689796173912$

(46) Zhang, W.; Wang, K.; Li, J.; Lin, Z.; Song, S.; Huang, S.; Liu Y.; Nie, F.; Zhang, Q. Stabilization of the Pentazolate Anion in a Zeolitic Architecture with Na $20 \mathrm{~N} 60$ and Na 24 N 60 Nanocages. Angew. Chemie Int. Ed. 2018, 57 (10), 2592-2595. https:// doi.org/10.1002/anie.201710602.

(47) Steele, B. A.; Oleynik, I. I. Sodium Pentazolate: A Nitrogen Rich High Energy Density Material. Chem. Phys. Lett. 2016, 643, 21-26. https://doi.org/10.1016/j.cplett.2015.11.008.

(48) Hanfland, M.; Loa, I.; Syassen, K. Sodium under Pressure: Bcc to Fcc Structural Transition and Pressure-Volume Relation to 100 GPa. Phys. Rev. B - Condens. Matter Mater. Phys. 2002, 65 (18), 1841091-1841098. https://doi.org/10.1103/ PhysRevB.65.184109.

(49) O’Keeffe, M.; Eddaoudi, M.; Li, H.; Reineke, T.; Yaghi, O. M. Frameworks for Extended Solids: Geometrical Design Principles. J. Solid State Chem. 2000, 152 (1), 3-20. https://doi.org/ 10.1006/jssc. 2000.8723 .

(50) Kovács, A. Coordination of N2 Ligands to Lanthanum: The Complexes La (N2)1-8. Struct. Chem. 2018, 29 (6), 1825-1837. https://doi.org/10.1007/s11224-018-1177-2.

(51) Lee, K.; Kim, S. W.; Toda, Y.; Matsuishi, S.; Hosono, H. Dicalcium Nitride as a Two-Dimensional Electride with an Anionic Electron Layer. Nature 2013, 494 (7437), 336-340. https:// doi.org/10.1038/nature11812.

(52) Prots, Y.; Auffermann, G.; Tovar, M.; Kniep, R. Sr4N3: A Hitherto Missing Member in the Nitrogen Pressure Reaction Series $\mathrm{Sr} 2 \mathrm{~N} \rightarrow \mathrm{Sr} 4 \mathrm{~N} 3 \rightarrow \mathrm{SrN} \rightarrow \mathrm{SrN} 2$. Angew. Chemie Int. Ed. 2002, 41 ( 13 ), $2288-2290$. ht t p : // doi.org/ $10.1002 / 1521-3773(20020703) 41: 13<2288:$ :AIDANIE2288>3.0.CO;2-I

(53) Schneider, S. B.; Seibald, M.; Deringer, V. L.; Stoffel, R. P.; Frankovsky, R.; Friederichs, G. M.; Laqua, H.; Duppel, V.; Jeschke, G.; Dronskowski, R.; et al. High-Pressure Synthesis and Characterization of Li2Ca 3[N2]3 - An Uncommon Metallic Diazenide with [N2]2- Ions. J. Am. Chem. Soc. 2013, 135 (44), 16668-16679. https://doi.org/10.1021/ja408816t. 

2002. https://doi.org/10.5860/choice.40-6428.

(55) Potvin, H.; Back, M. H. A Study of the Decomposition of Sodium Azide Using Differential Thermal Analysis. Can. J. Chem. 1973, 51 (2), 183-186. https://doi.org/10.1139/v73-028.

(56) Kloß, S. D.; Schnick, W. Nitridophosphates: A Success Story of Nitride Synthesis. Angew. Chemie Int. Ed. 2019, 58 (24), 7933 7944. https://doi.org/10.1002/anie.201812791.

(57) Karau, F. W.; Schnick, W. High-Pressure Synthesis and X-Ray Powder Structure Determination of the Nitridophosphate. $J$. Solid State Chem. 2005, 178 (1), 135-141. https://doi.org/ 10.1016/j.jssc.2004.10.034

(58) Karau, F. W.; Seyfarth, L.; Oeckler, O.; Senker, J.; Landskron, K.; Schnick, W. The Stuffed Framework Structure of SrP2N4: Challenges to Synthesis and Crystal Structure Determination. Chem. - A Eur. J. 2007, 13 (24), 6841-6852. https://doi.org/ 10.1002/chem.200700216.

(59) Landskron, K.; Irran, E.; Schnick, W. High-Temperature HighPressure Synthesis of the Highly Condensed Nitridophosphates NaP4N7, KP4N7, RbP4N7, and CsP4N7 and Their CrystalStructure Determinations by X-Ray Powder Diffraction. Chem. A Eur. J. 1999, 5 (9), 2548-2553. https://doi.org/10.1002/ ( S I C I ) $1521-3765$ (19990903) $5: 9<2548:$ : A I D CHEM2548>3.3.CO;2-N.

(60) Gillan, E. G.; Kaner, R. B. Rapid Solid-State Synthesis of Refractory Nitrides. Inorg. Chem. 1994, 33 (25), 5693-5700. https://doi.org/10.1021/ic00103a015.

(61) Lei, L.; Zhang, L. Recent Advance in High-Pressure Solid-State Metathesis Reactions. Matter Radiat. Extrem. 2018, 3 (3), 95103. https://doi.org/10.1016/j.mre.2017.12.003.

(62) Kawamura, F.; Yusa, H.; Taniguchi, T. Synthesis of Hexagonal Phases of WN and W $2.25 \mathrm{~N} 3$ by High-Pressure Metathesis Reaction. J. Am. Ceram. Soc. 2018, 101 (2), 949-956. https:// doi.org/10.1111/jace.15235.

(63) Kawamura, F.; Yamada, N.; Cao, X.; Imai, M.; Taniguchi, T. The Bandgap of $\mathrm{ZnSnN} 2$ with a Disordered-Wurtzite Structure. Jpn. J. Appl. Phys. 2019, 58 (SC), SC1034. https://doi.org/ 10.7567/1347-4065/ab0ace.

(64) Zhu, S.; Peng, F.; Liu, H.; Majumdar, A.; Gao, T.; Yao, Y. Stable Calcium Nitrides at Ambient and High Pressures. Inorg. Chem. 2016, 55 (15), 7550-7555. https://doi.org/10.1021/acs.inorgchem.6b00948.

(65) Peng, F.; Han, Y.; Liu, H.; Yao, Y. Exotic Stable Cesium Polynitrides at High Pressure. Sci. Rep. 2015, 5, 16902. https://doi.org/ 10.1038/srep16902. 


\section{SYNOPSIS}

Here using a controlled decomposition of sodium azide $\mathrm{NaN}_{3}$ at high pressure conditions two novel compounds $\mathrm{Na}_{3}\left(\mathrm{~N}_{2}\right)_{4}$ and $\mathrm{NaN}_{2}$ were synthesized. Both contain dinitrogen anions. $\mathrm{NaN}_{2}$ might be the common intermediate in high-pressure solid-state metathesis reactions where $\mathrm{NaN}_{3}$ is used as a source of nitrogen. $\mathrm{Na}_{3}\left(\mathrm{~N}_{2}\right)_{4}$ opens a new class of compounds, where $\left[\mathrm{N}_{2}\right]$ units accommodate a non-integer formal charge.

For Table of Contents Only

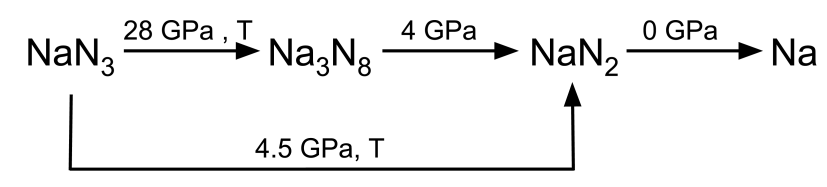

$0000,8 \& 800$

\& $1000.0 \% \quad \mathrm{Na}_{3}\left(\mathrm{~N}_{2}\right)_{4}$

का

\& 80000 \& 21 non-integer formal

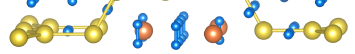

charge on $\left[\mathrm{N}_{2}\right]^{0.75-}$ 